\title{
LONG-TERM MEASUREMENTS OF ENERGY PRODUCTION OF SOLAR PHOTOVOLTAIC PANELS
}

Ilze Pelece, Adolfs Rucins, Semjons Ivanovs

Latvia University of Life Sciences and Technologies, Latvia

ilze.pelece@1lu.1v, adolfs.rucins@1lu.1v, semjons@apollo.lv

\begin{abstract}
This article deals with the forecast of solar energy in Latvia. Latvia characterizes with rather low irradiances and high nebulosity, but long days in summer in comparison to traditional solar energy using in the southern countries. Two stationary mounted and two tracking to sun solar photovoltaic (PV) panels Solet 60.6WF-250, the surface area 1.6 square meters for each, are studied in this article. Measurements are done in Ulbroka, Latvia, on the roof of the Ulbroka Scientific Centre. Energy produced by panels is entered into the public electricity grid using the solar micro invertor Enphase with MPPM function and registered by Envoy. The Enphase Micro inverter converts the DC output of the PV module into grid-compliant AC power and continuously adjusts electrical parameters for the maximum power gain. Daily energy sums are registered from April 1 till December 31 of 2020. Daily energy sum from the mentioned system can reach $10 \mathrm{kWh}$ on a clear summer day, but in November and December the daily energy sum produced is near to zero. Total energy gain from the mentioned system (with total area of solar panels 6.4 square meters) in the whole mentioned time period is approximately 940 $\mathrm{kWh}$. Measurements are compared to theoretical daily energy sums of solar radiation taking into account also nebulosity. Data on the nebulosity are taken from the public homepage of the Latvia Environment, Geology and Meteorology Centre. Such comparison allows to estimate real efficiency of panels. We obtained the efficiency 12$13 \%$, what is little bit less than $15 \%$ given in the technical characteristics of the panel given by the producer. Described calculations can be used for forecast of received solar energy if nebulosity forecast (real or many years mean for every day) is known. The method can be used for any location worldwide.
\end{abstract}

Keywords: solar energy, photovoltaic, calculated, forecast.

\section{Introduction}

The article deals with use of solar energy in Latvia. Although Latvia is located more in the north than traditional solar energy using countries and the weather there is rather unstable and often cloudy, the length of a day in summer is 17 hours, and average global radiation on horizontal surface in June and July is $220-230 \mathrm{~W} \cdot \mathrm{m}^{-2}$ [1]. The aim of this article is to compare the calculated daily energy sums with the measured energy gain from stationary tilted and tracking sun solar panels and with global solar irradiance on horizontal surface measured at the meteostation. Such comparison allows to forecast available energy gain from different forms of solar PV panels and collectors. Such forecasts are very important in making decisions related to installing of solar energy devices [2]. There are methods allowing to forecast global solar radiation on horizontal surface [3; 4], and we develop a method allowing to forecast energy gain from these data. Some authors, for example, [3, 5], offer also methods how to forecast solar irradiation, if measured data are not available. There can be found in literature [6] similar methods for forecasting energy gain from 3-D surfaces, but this method is rather complicated. We offer a simpler method for simpler surfaces. In this article we show use of the method for flat surfaces, but it can be used also for spherical and cylindrical ones.

In review article [7] different forecasting methods are discussed. Time-series is a sequence of observations on a parameter measured at successive points in time [8]. The statistical methods were used to reconstruct the relations between the past meteorological parameters and hourly irradiance [9]. The statistical model does not require the internal state information of the system to model it [10]. According to [11], forecast methods can be classified depending on the period of the forecast: long-term forecasts deal with more than one year, mid-term from 1 month to 1 year, short-term from several hours to one week, very short-time prediction for several minutes up to several hours. The method proposed in this article can be used as short-term prediction from real weather prognoses or as mid-term or long-term from climatic data.

\section{Materials and methods}

Measurements have been done at Ulbroka, on the roof of the Ulbroka Research Centre (coordinates $56^{\circ} 56^{\prime} 35^{\prime \prime}$ N 24 $4^{\circ} 17^{\prime} 07^{\prime \prime}$ E). Four solar panels Solet 60.6-WF-250 were used. Technical information of panels is given in Table 1 . 
Two panels were mounted stationary at $40^{\circ}$ tilt facing to the south, the other two were tracking to the sun. Daily energy sums were measured using electromechanical electric meters for stationary and tracking panels separately (measurements are done from April 1 to June 16 of 2020), and with Enphase Microinverter System total of all four panels (from April 1 till December 15 of 2020). This system consists of Enphase Microinverter (we used Enphase M215 microinverters), Enphase Envoy Communications Gateway and Enphase Enlighten web-based monitoring and analysis software.

Technical data of solar panel Solet 60.6-WF-250

Table 1

\begin{tabular}{|l|c|c|}
\hline \multicolumn{1}{|c|}{ Parameter } & Designation & Value \\
\hline Maximum power & $P_{\max }$ & $255 \mathrm{~W}$ \\
\hline Voltage at maximum power point & $V_{\operatorname{mpp}}$ & $30.9 \mathrm{~V}$ \\
\hline Open voltage & $V_{o c}$ & $38.4 \mathrm{~V}$ \\
\hline Current at maximum power point & $I_{\mathrm{mpp}}$ & $8.06 \mathrm{~A}$ \\
\hline Short circuit current & $I_{s c}$ & $8.6 \mathrm{~A}$ \\
\hline Thermal coefficient of power & $\% \cdot \mathrm{K}^{-1}$ & $(-0.47)$ \\
\hline Size & $\mathrm{mm}$ & $1640 * 992 * 45$ \\
\hline Mass & $\mathrm{kg}$ & 22 \\
\hline Energy conversion ratio & $\%$ eff & 15 \\
\hline
\end{tabular}

Energy gain from solar panels was compared with the theoretical one, calculated using the methodology described in [12], using transparency of the atmosphere 0.78 and diffused radiation $60 \mathrm{~W} \cdot \mathrm{m}^{-2}$. Energy received by tilted or tracking to sun surface is calculated after every 15 minutes, summed throughout the day and converted to $\mathrm{kWh}$. Impact of clouds was taken into account by comparing these data with solar irradiance on the horizontal surface measured by the nearest meteostation of the Latvian Environment, Geology and Meteorology Centre. Coordinates of the station Riga-University are $56^{\circ} 57^{\prime} 17.36937^{\prime \prime} \mathrm{N} 024^{\circ} 06^{\prime} 16.89935^{\prime \prime} \mathrm{E}$, what means the distance from the station to Ulbroka is $10 \mathrm{~km}$. The meteostation measures hourly mean irradiance on the horizontal surface. Daily energy sum is obtained as:

$$
E_{m}=\sum \frac{I \cdot 3600}{3.6 \cdot 10^{6}}=\frac{\sum I}{1000},
$$

where $\quad E_{m}-$ daily energy sum measured in the meteostation, $\mathrm{kWh}$;

$$
I \text {-irradiance, } \mathrm{W} \mathrm{m}^{-2} \text {. }
$$

Comparison of daily energy sums calculated theoretically and those measured in the meteostation is given in Fig. 1.

From this picture we can see that at clear days there is good coincidence between the calculated values and the measured ones. We can assume that the impact of clouds would be the same as on the horizontal surface also on the tilted surface and on the tracking sun one. Then the calculated values of daily energy sums on those surfaces would be

$$
E_{c t}=\frac{E_{c t 0} \cdot E_{m h}}{E_{c h 0}},
$$

where $E_{c t}-$ calculated daily energy sum of tracking sun surface, $\mathrm{kWh} \cdot \mathrm{m}^{-2}$;

$E_{c t 0}$ - calculated daily energy sum of sun-tracking surface at clear weather, $\mathrm{kWh} \cdot \mathrm{m}^{-2}$;

$E_{m h}$ - measured daily energy sum of horizontal surface, $\mathrm{kWh} \cdot \mathrm{m}^{-2}$;

$E_{c h 0}-$ calculated daily energy sum on horizontal surface at clear weather, $\mathrm{kWh} \cdot \mathrm{m}^{-2}$;

and

$$
E_{c s}=\frac{E_{c s 0} \cdot E_{m h}}{E_{c h 0}},
$$

where $E_{c s}$ - calculated daily energy sum of slope surface, $\mathrm{kWh} \cdot \mathrm{m}^{-2}$;

$E_{c s 0}-$ calculated daily energy sum of slope surface at clear weather, $\mathrm{kWh} \cdot \mathrm{m}^{-2}$; 
$E_{m h}-$ measured daily energy sum of horizontal surface, $\mathrm{kWh} \cdot \mathrm{m}^{-2}$;

$E_{c h 0}$ - calculated daily energy sum on horizontal surface at clear weather, $\mathrm{kWh} \cdot \mathrm{m}^{-2}$.

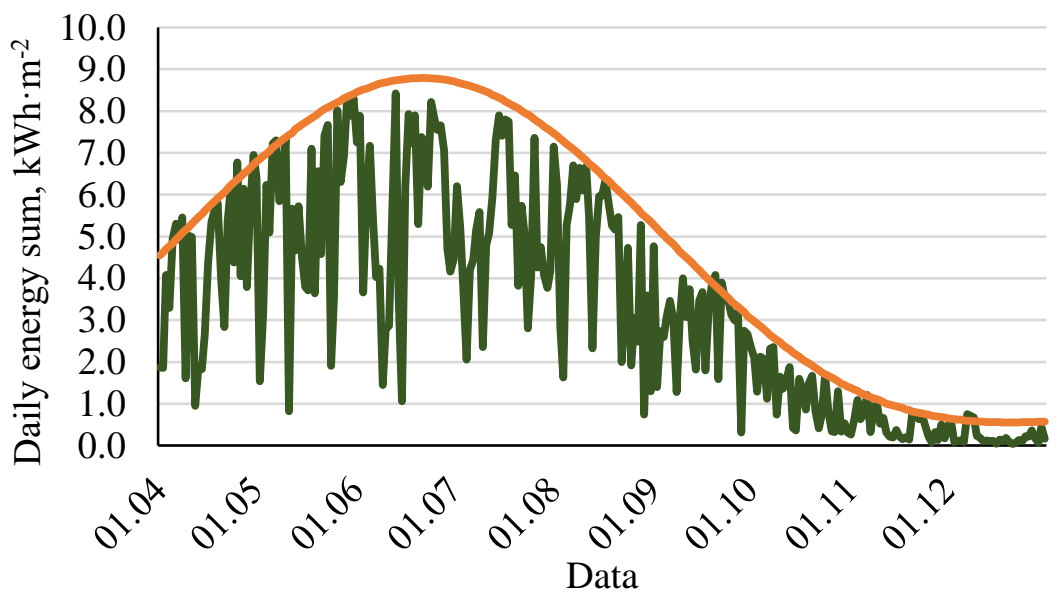

Fig. 1. Comparison of daily energy sums calculated theoretically (orange line) with those measured in the meteostation (green line)

Then these calculated daily energy sums, which take into account also cloudiness, are compared to the daily energy gain from the PV panels.

\section{Results and discussion}

Dependence of the daily energy sums produced by stationary mounted and tracking the sun PV panels on those measured by the meteostation is shown in Fig. 2.

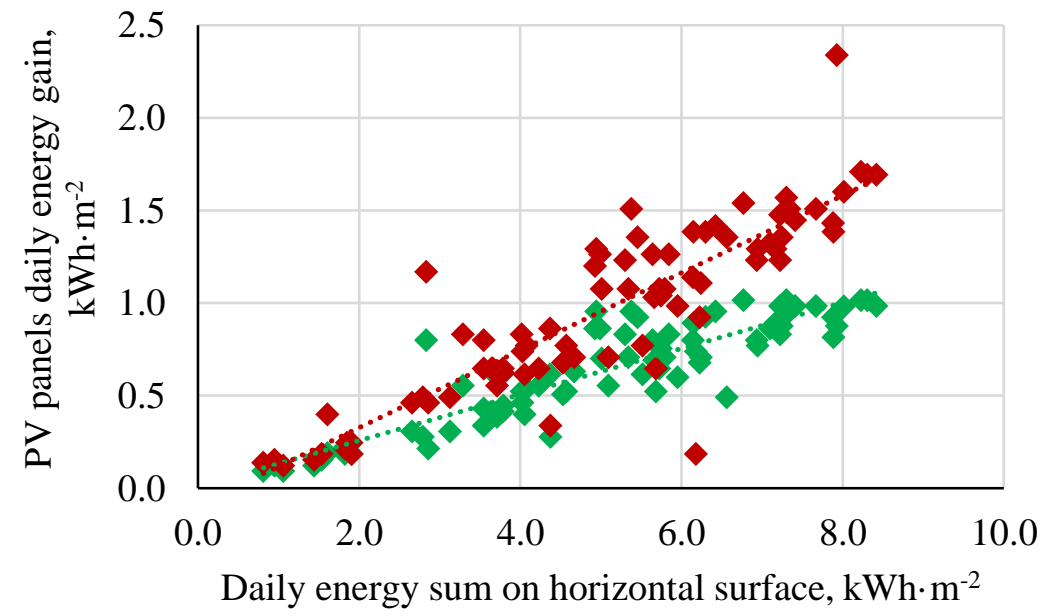

Fig.2. Dependence of daily energy sums produced by stationary mounted (green dots) and tracking sun (red dots) PV panels

This plot shows rather linear dependence with the determination factor $R^{2}=0.80$ for the stationary panel and 0.77 for the tracking one. Slope of the line characterises effectiveness of the panel, taking into account both the energy conversation rate of the panel itself and positioning of the panel. This slope is $0.124 \pm 0.041$ for the stationary mounted panel and $0.209 \pm 0.075$ for the tracking sun one.

Comparison of the measured and calculated daily energy sums of stationary mounted and tracking the sun PV panels is shown in Fig. 3.

Here in calculations the energy conversation rate of the panel is not taken into account, but the measured energy is recalculated on the surface area of the panel. Therefore, the determination factor $R^{2}$, which is 0.86 for the stationary mounted panel and 0.80 for tracking sun one, characterizes daily accuracy of the method. Deviations may occur also because measuring of energy gain from panels and 
of solar irradiance (from which the impact of clouds was obtained) did not occur in the same place. As it was already mentioned, the distance between the solar panels and the meteostation was $10 \mathrm{~km}$.

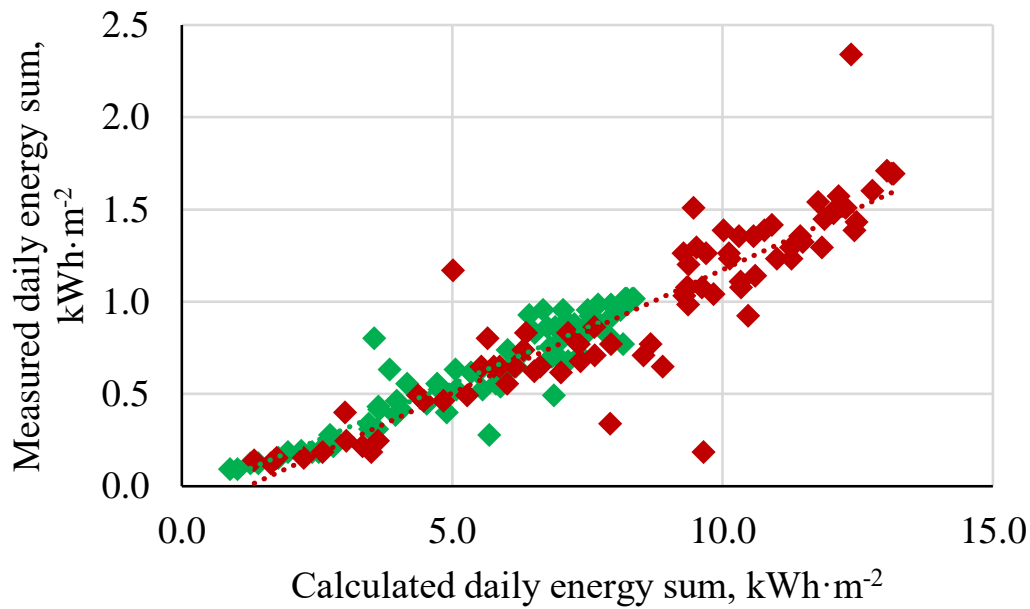

Fig. 3. Comparison of measured and calculated daily energy sums, green dots - stationary mounted panel, red dots - tracking sun panel

Slope of the line in this case characterises the energy conversation rate of panels. We obtained $0.122 \pm 0.036$ for the stationary panel and $0.134 \pm 0.73$ for the tracking one, while the producers' given value is 0.15 . Such difference may be because of non-optimal working conditions of panels, for example, low irradiance, therefore also the tracking sun panel, which receives more solar radiation, shows better value than the stationary mounted one.

Fig. 4 shows comparison of the measured daily energy gain from stationary mounted and tracking sun panels.

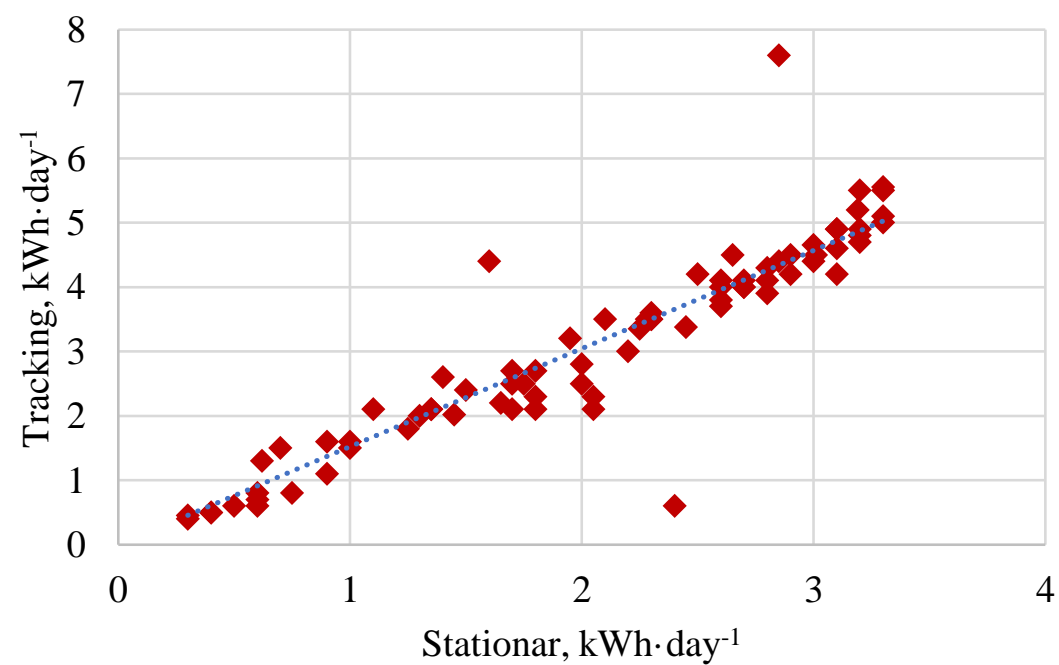

Fig. 4. Daily energy gain from stationary mounted and tracking PV panels

Slope of the line is 1.52 (with intercept set to zero), what means that the tracking panel produces 1.52 times more energy than the stationary mounted one, with the determination factor $R^{2}=0.83$. These results are comparable with those obtained in [13], where overall ratio of energy gain from tracking to stationary panels is found 1.41 , but considering only clear days, it is 1.59 .

Fig. 5 shows comparison of the results measured with electromechanical electric counters for stationary mounted and tracking panels separately with those registered by Envoy, which are total from both panels. Good coincidence has been obtained (slope 0.97 and determination factor $R^{2}=0.93$ ), what means that both devices measure the same value. 


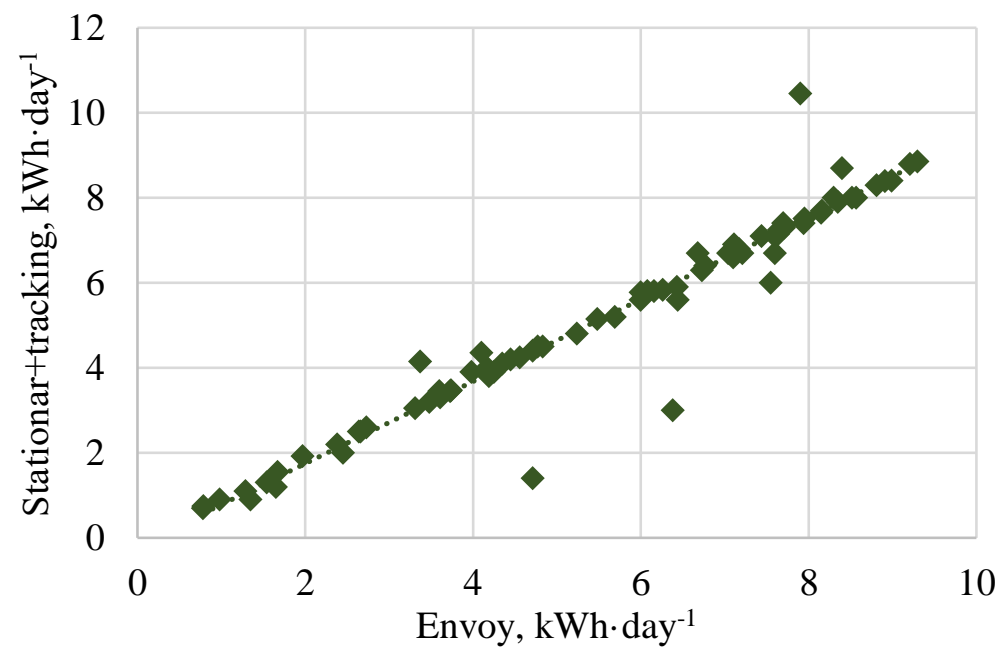

Fig. 5. Comparison of results measured with electromechanical electric counters for stationary mounted and tracking panels separately with those registered by Envoy, which are total from both panels

Plot of the daily energy sums registered by Envoy via the calculated ones from April 1 till December 31 gives slope of the line 0.11 (intercept is set to zero) with the determination factor $R^{2}=0.82$, but large scattering of points is observed at smaller daily energy sums. It means that at low irradiances PV panels do not work properly.

Therefore, we plot the same graph for the summer season, April 1 till August 31, separately (Fig.6). In this case we obtain a slope of the line (with intercept set to zero) $0.12 \pm 0.33$, which within error limits corresponds to the energy conversation ratio given by the producers $(0.15)$, and also the determination factor is better: $R^{2}=0.88$.

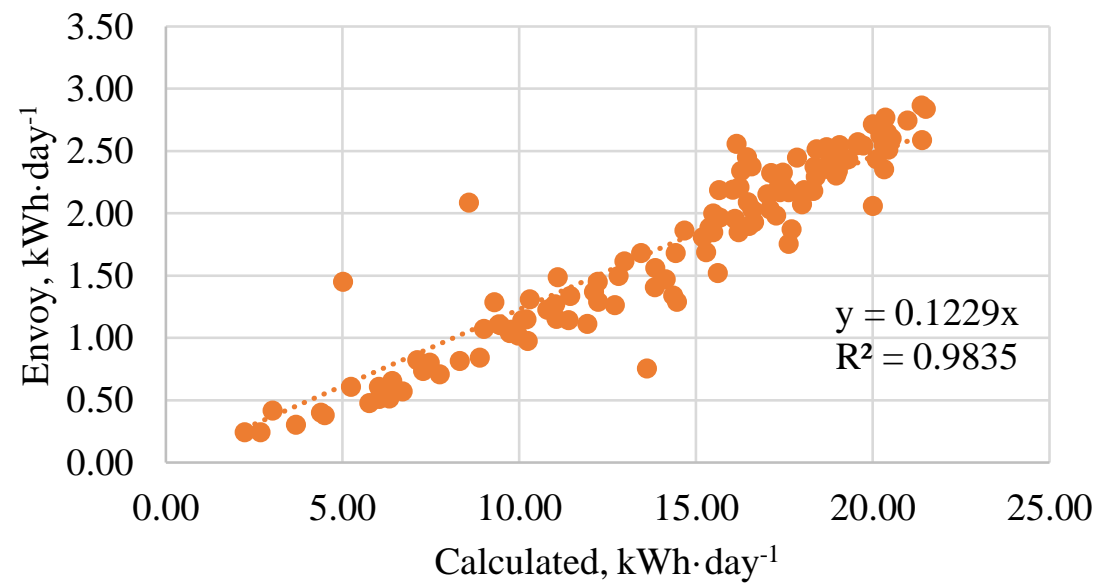

Fig. 6. Envoy registered daily energy sums against calculated ones, summer: April 1 till August 31

Monthly energy sum was the largest in July and reached $220 \mathrm{kWh}$, but in October and November it was only $10 \mathrm{kWh}$ and in December no significant amount of energy was obtained.

Further measurements are necessary to evaluate correctly the smallest irradiation at which PV panels work, and when they start to work in spring. The authors believe that this could be the beginning of March or even mid-February, because in Latvia spring is less cloudy than the autumn and winter.

\section{Conclusions}

1. Based on good coincidence between the calculated and measured values, the proposed method can be used for forecasting of received solar energy. 
2. Sun-tracking PV panel produces 1.52 times more energy than a stationary mounted one at the same time.

\section{Acknowledgements}

The authors are very grateful to Henrik Putan for his great contribution to the installation of equipment and measurements.

\section{References}

[1] Climatic data. [oline] [21.03.2021] Available at: https://www4.meteo.lv/radiacijas-atlants/

[2] Ghadah Alkhayata, Rashid Mehmood A review and taxonomy of wind and solar energy forecasting methods based on deep learning. Energy and AI 4(2021)100060

[3] Josselin L. G. L. Sallea, Jordi Badosab, Mathieu Davida etc. Added-value of ensemble prediction system on the quality of solar irradiance probabilistic forecasts. Renewable Energy 162, 2020, pp. 1321-1339.

[4] Dazhi Yanga, Stefano Alessandrinib, Javier Antonanzasc etc. Verification of deterministic solar forecasts. Solar Energy 210, 2020, pp. 20-37.

[5] A. Ben Othmana, K. Belkilania, M. Besbes. Global solar radiation on tilted surfaces in Tunisia: Measurement, estimation and gained energy assessments. Energy Reports 4, 2018, pp. 101-109

[6] E. Roohollahia, M. A. Mehrabiana, M. Abdolzadeh. Prediction of solar energy gain on 3-D geometries. Energy and Buildings 62, 2013, pp. 315-322

[7] Montgomery DC, Jennings CL, Kulahci M. Introduction to time series analysis and forecasting. John Wiley \& Sons; 2015.

[8] Sobrina Sobri, Sam Koohi-Kamali, Nasrudin Abd. Rahim. Solar photovoltaic generation forecasting methods: A review Energy Conversion and Management 156, 2018, pp. 459-497.

[9] Cornaro C, Pierro M, Bucci F. Master optimization process based on neural networks ensemble for 24-h solar irradiance forecast. Sol Energy 2015; 111, pp. 297-312.

[10] Antonanzas J, Osorio N, Escobar R, Urraca R, Martinez-de-Pison F, AntonanzasTorres F. Review of photovoltaic power forecasting. Sol Energy 2016; 136 pp. 78-111.

[11] Raza MQ, Nadarajah M, Ekanayake C. On recent advances in PV output power forecast. Sol Energy 2016;136:125-44

[12] Pelece I. Calculations and measurenments of energy gain from semispherical solar collector. Proceedings of $4^{\text {th }}$ International conference "Trends in Agricultural Engineering", September 7-10, 2010, Prague, Czech Republic, pp. 468-472.

[13]Zagorska V., Kancevica L., Putans H., Ziemelis I. Efficiency of fixed and tracking photovoltaic panel. Proceedings of International conference "Engineering for Rural Development", May 29-30, 2014, Jelgava, Latvia, pp. 301-305 